\title{
Quantification of toxic hydrocarbon target compounds in engine exhaust and air by aluminum oxide porous-layer open- tubular capillary gas chromatography-mass spectrometry using isotopically labeled internal standards
}

\author{
Cheng-Chiech Huang ${ }^{a}$, Yunn-Chyi Chen ${ }^{a}$, Guor-Rong Her ${ }^{a}{ }^{\text {,*}}$, Chang-Chuan Chan ${ }^{\mathrm{b}}$ \\ ${ }^{3}$ Department of Chemistry, National Taiwan University, Taipei, Taiwan \\ 'Institute of Occupational Medicine and Industrial Hygiene, College of Public Health, National Taiwan University, Taipei, \\ Taiwan
}

First received 20 July 1995; revised manuscript received 17 October 1995; accepted 20 October 1995

\begin{abstract}
A method for the determination of 1,3-butadiene, benzene and toluene in ambient air and engine exhaust is described. Air was sampled with a canister and then analysed by $\mathrm{Al}_{2} \mathrm{O}_{3}$-coated porous-layer open-tubular (PLOT) capillary gas chromatography-mass spectrometry. The PLOT column provides better resolution for light hydrocarbons and also alleviates the need of using a sub-ambient oven temperature. While the retention times might change owing to the adsorption of moisture, the use of mass spectrometry for detection and isotopically labeled analytes as the internal standards greatly improved the confidence of identification. The heating of solid deuterated butadiene sulfone provides a convenient method for the preparation of deuterated butadiene standard gas. To couple a wide-bore PLOT column with a bench-top mass spectrometer, a pressure gradient and open split interface were used in order to maintain the chromatographic resolution and limit the running time within a reasonable range.
\end{abstract}

Keywords: Environmental analysis; Air analysis; Sample handling; 1,3-Butadiene; Benzene; Toluene; Hydrocarbons; Volatile organic compounds

\section{Introduction}

Many air contaminants are of great environmental concern because of their implications for human health $[1,2]$. In urban area, automobile exhaust has been identified as one of the most important sources of toxic hydrocarbons $[3,4]$.

* Corresponding author.
An analytical method of high sensitivity and high accuracy is needed not only for assessing health risks but also for developing control technology and setting standards for automobile emissions.

Conventional gas-liquid capillary columns such as the DB-1 column are often used in the analysis of volatile organic compounds. Recently, the aluminum oxide-coated fused-silica porouslayer open-tubular (PLOT) capillary column has 
gained popularity in the analysis of hydrocarbons (HCs) [5-10]. The resolving power of the PLOT column is superior to that of conventional columns for light hydrocarbons [11-13]. Moreover, because the separation process with a PLOT column is based on adsorption chromatography, the elution temperatures are much higher than with conventional columns, thus eliminating the need to use an initial sub-ambient oven temperature [14].

Although the PLOT column has the advantages of a better resolving power for light hydrocarbons and avoidance of using an initial subambient oven temperature, the retention time may change owing to the adsorption of polar molecules such as water and methanol on the active aluminum oxide layer. In the analysis of field samples, the continuous change in retention times owing to the progressive adsorption of water increases the uncertainty in the identification of target compounds $[9,15]$. To circumvent this problem, the PLOT column was coupled with a bench top gas chromatography-mass spectrometry (GC-MS) system and isotopically labeled internal standards were used. We report in this paper the application of this approach to the analysis of toxic hydrocarbons.

\section{Experimental}

\subsection{Chemicals and standards}

$\mathrm{C}_{1}-\mathrm{C}_{4}$ hydrocarbon standard gases were purchased form Scott Specialty Gases (Durham, NC, USA). Benzene, toluene, ethylbenzene, $p$-xylene and $o$-xylene were obtained from Sigma (St. Louis, MO, USA). Gas standards were prepared by injection of gases from Scotty cans (or liquid for BTEX) into a 2-1 dilution bottle. These standards were diluted subsequently to the desired concentrations with zero air.

\subsection{Isotopically labeled internal standards}

Isotopically labeled internal standards, $\left[{ }^{2} \mathrm{H}_{6}\right]$ benzene and $\left[{ }^{2} \mathrm{H}_{8}\right]$ toluene, were purchased from Sigma and had a minimum isotopic purity of $99.0 \%$ of deuterium. $\left[1,1,4,4-{ }^{2} \mathrm{H}_{4}\right]$ Butadiene was prepared from $\left[2,2,5,5-{ }^{2} \mathrm{H}_{4}\right]$ butadiene sulfone [16] obtained from Aldrich (Milwaukee, WI, USA). The deuterium compound was weighed into a static dilution bottle (SDB), evacuated to $1.3 \mathrm{kPa}$ by a vacuum pump and then heated at $120^{\circ} \mathrm{C}$ for $15 \mathrm{~h}$. After the reaction, the bottlc was filled with zero air to $101.3 \mathrm{kPa}$. The yield of the reaction was quantified by $\mathrm{GC}$-flamc ionization detection (FID) with pure 1,3-butadiene standard.

\subsection{Sampling}

Summa electropolished stainless-steel canisters (6 1) were purchased from Andersen Samplers (Atlanta, GA, USA). Before use, the canisters were heated to $90^{\circ} \mathrm{C}$ and then cleaned with repetitive evacuation and refilling with humidified zero air. The cleaned canisters were checked with GC-MS for the blank level before sampling. Through a filter (pore size $5 \mu \mathrm{m}$ ), air sample was drawn into the canister by vacuum. To obtain an average concentration in samples of volatile organic compounds (VOCs) from the roadways of Taipei city, it was found that with the sampler evacuated to $6.7 \mathrm{~Pa}$, a calibrated metering valve could provide a relatively constant flow of $50 \mathrm{ml} / \mathrm{min}$ (within $20 \%$ ) within a 50-min sampling period.

The sampling of tail-pipe exhausts was conducted by standard emission testing procedures in a dynamometer. European Community Emission (ECE) and Federal Test Procedures (FTP) driving cycles were used for motorcycles and automobiles, respectively. The sampling points were all located at the three-way valve prior to the analyzers of the regulated criteria pollutants. The cleaned and evacuated canisters were attached to the three-way valve and 61 of tail-pipe exhaust were collected within $1 \mathrm{~min}$.

After the sampling, zero air was discharged into the canister until the canister pressure reached $110.3 \mathrm{kPa}$. This step is necessary for providing a positive pressure for the injection of air samples into the modified Model 6000 Aero Trap Desorber (Tekmar, Cincinnati, OH, USA). 


\subsection{Sample introduction}

The Tekmar 6000 Thermo Desurber, which was designed for the analysis of VOCs adsorbed in an adsorption tube, was modified for the introduction of whole air into the system as shown in Fig. 1. The canister was attached to a heated (ca. $80^{\circ} \mathrm{C}$ ) $1.6 \mathrm{~mm}$ O.D. stainless-steel transfer line. The transfer linc and helium purge gas were connected to a three-way valve on the desorber with a low-dead-volume T-union (Swagelok) injector. Deuterium-labeled internal standards were injected into the T-union injector by a gas-tight syringe when real sample was carried from the canister. The vent port of the desorber was connected to a needle valve and a mass flow meter (Aalborg Instruments \& Controls, Monsey, NY, USA). The output of the flow meter was recorded with a microcomputer and
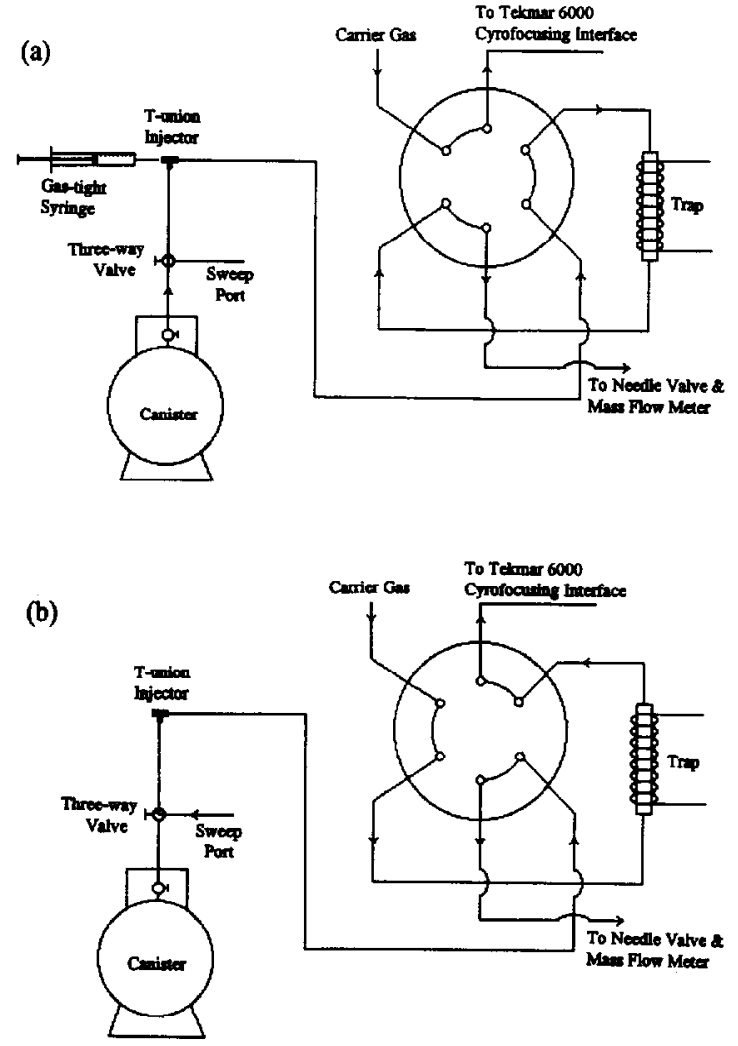

Fig. 1. Modified Tekmar 6000 Thermo Desorber. (a) Sample introduction mode; (b) desorption mode. then integrated to calculate the total injection volume. VOCs concentrated in the cryotrap were desorbed at $200^{\circ} \mathrm{C}$ for $6 \mathrm{~min}$ at a flow-rate of 10 $\mathrm{ml} / \mathrm{min}$. The desorbed sample was refocused on to the cryogenic interface of a capillary column, which was cooled with liquid nitrogen to $-180^{\circ} \mathrm{C}$, and then rapidly desorbed to $200^{\circ} \mathrm{C}$ within $1 \mathrm{~min}$.

In this modified cryotrap system, samples and internal standard were introduced into the instrument separately. The validity of this arrangement was chccked by comparison with a method of premixing samples and internal standard before the analysis. By determining butadiene standard in Summa canisters, the results of these two different approaches were found to be very similar ( $7 \%$ with triplicate analysis).

\subsection{GC-MS analysis}

Separation and identification were performed on an MD 800 benchtop GC-MS system (Fisons, Rodano, Italy). The separation capillary column was a $50 \mathrm{~m} \times 0.32 \mathrm{~mm}$ I.D. PLOT column coated with aluminum oxide and deactivated with potassium chloride (Chrompack, Middelburg, Netherlands). The pressure applied to the separation column was controlled by a GC-17A GC system (Shimadzu, Tokyo, Japan) with the capability of pressure programming. The mass spectrometer was operated in the selected-ion monitoring (SIM) mode for optimum sensitivity.

\section{Results and discussion}

Because of regulatory interest and toxicity, benzene, toluene, and 1,3-butadiene are the most often studied toxic hydrocarbons. For the determination of 1,3-butadiene, as expected, an $\mathrm{Al}_{2} \mathrm{O}_{3}$-coated PLOT capillary column provided better resolution than the conventional columns. For example, the differences in retention times between 1,3-butadiene and other $\mathrm{C}_{4} \mathrm{HCs}$ in the PLOT column were much greater than in a DB-5 column, as shown in Fig. 2. This advantage is important because 1,3-butadiene is often a minor component in $\mathrm{C}_{4} \mathrm{HCs}$ and baseline resolution is needed for the measurement of peak area with 


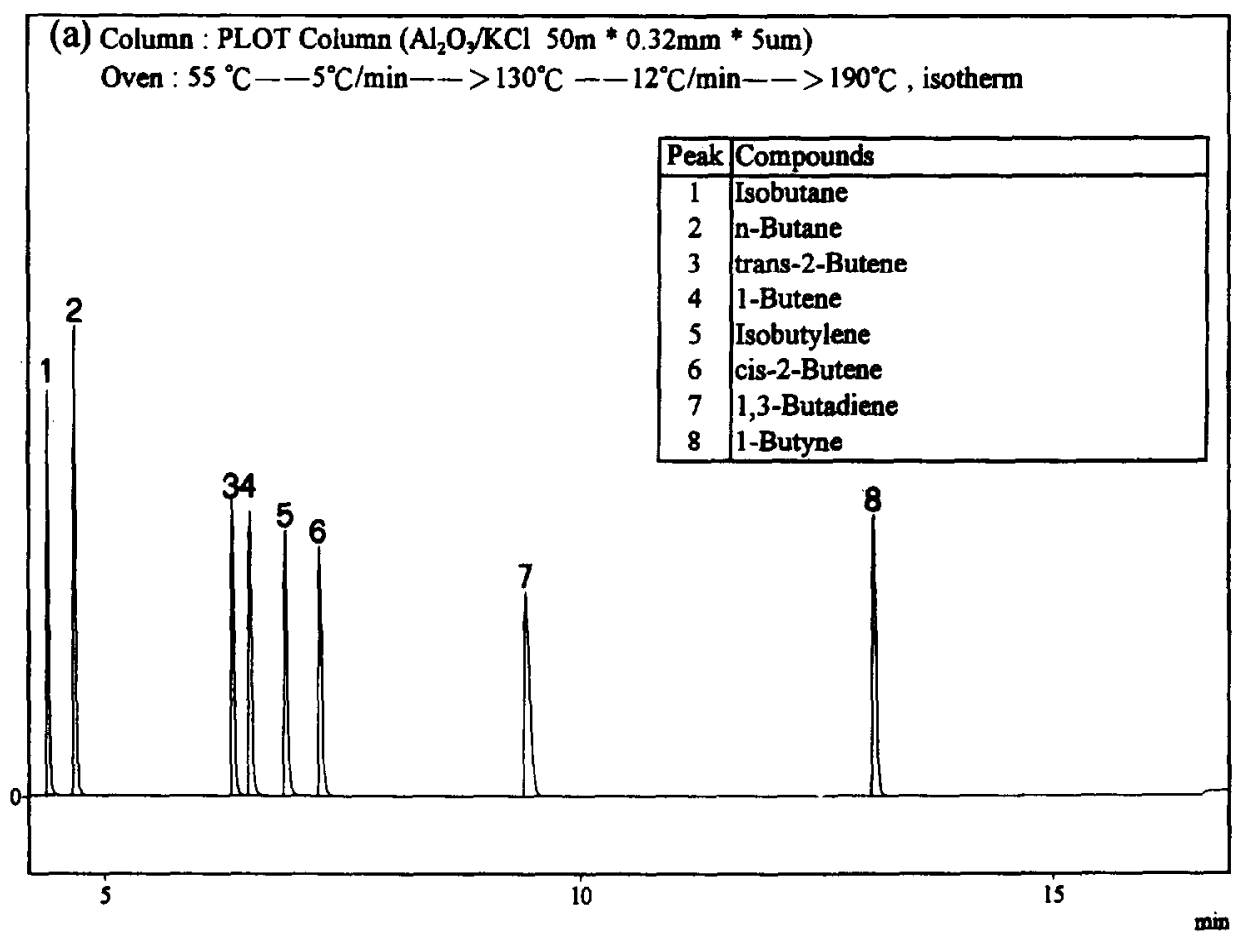

(b) Column : DB-5 Column $(30 \mathrm{~m} * 0.32 \mathrm{~mm} * 0.25 \mathrm{um})$

Oven : $-50^{\circ} \mathrm{C}--6^{\circ} \mathrm{C} / \mathrm{min}-->50^{\circ} \mathrm{C}$, isotherm

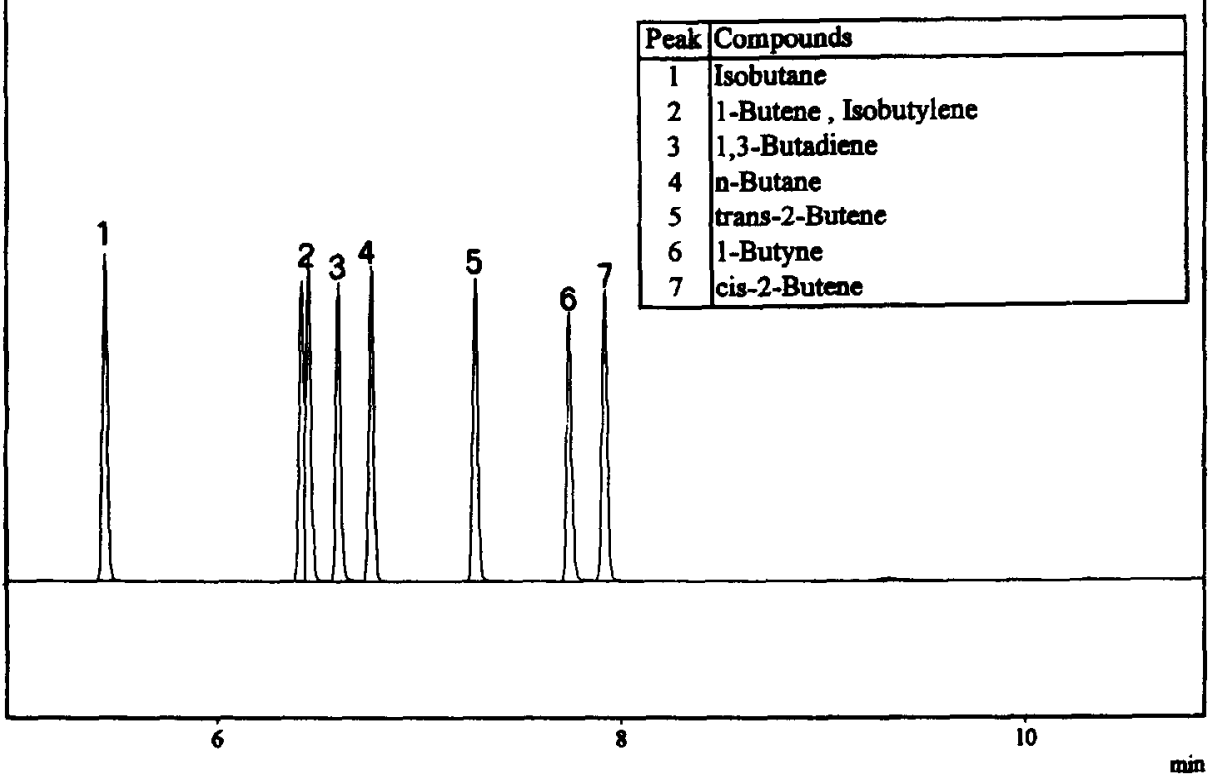

Fig. 2. Chromatograms of $\mathrm{C}_{4}$ hydrocarbons with (a) PLOT column and (b) DB-5 column. 


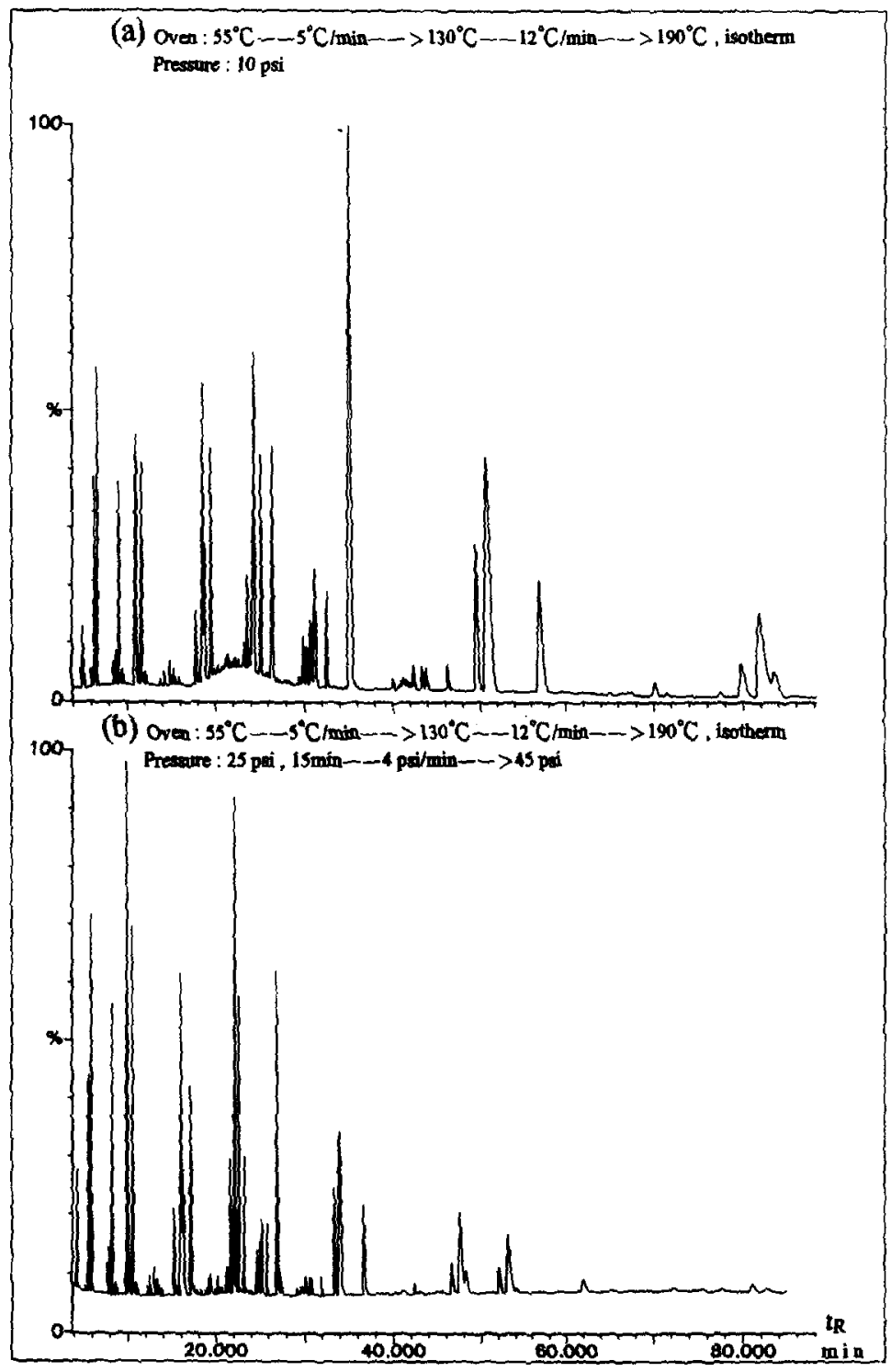

Fig. 3. Mass chromatograms of a real sample with (a) constant pressure and (b) pressure gradient.

high accuracy. In addition, a sub-ambient initial oven temperature was required in the analysis of $\mathrm{C}_{4} \mathrm{HCs}$ with the DB-5 column (Fig. 2b). This cryogenic procedure results in significant extra costs and inconvenience.

Among various GC detection methods, MS can provide the highest confidence in compound identification. The retention time along with molecular ion and fragment ions provide unambiguous assignments for most organic com- pounds. For many applications, the use of MS as a capillary $\mathrm{GC}$ detector proved to be the best, if not the only, technique to meet the requirement of high-confidence identification. The use of MS for detection with a PLOT column is even more significant because, as mentioned earlier, large variations in retention times occur owing to the progressive adsorption of water in the PLOT column, making identification difficult. Further, it has been reported that the selectivity of the 


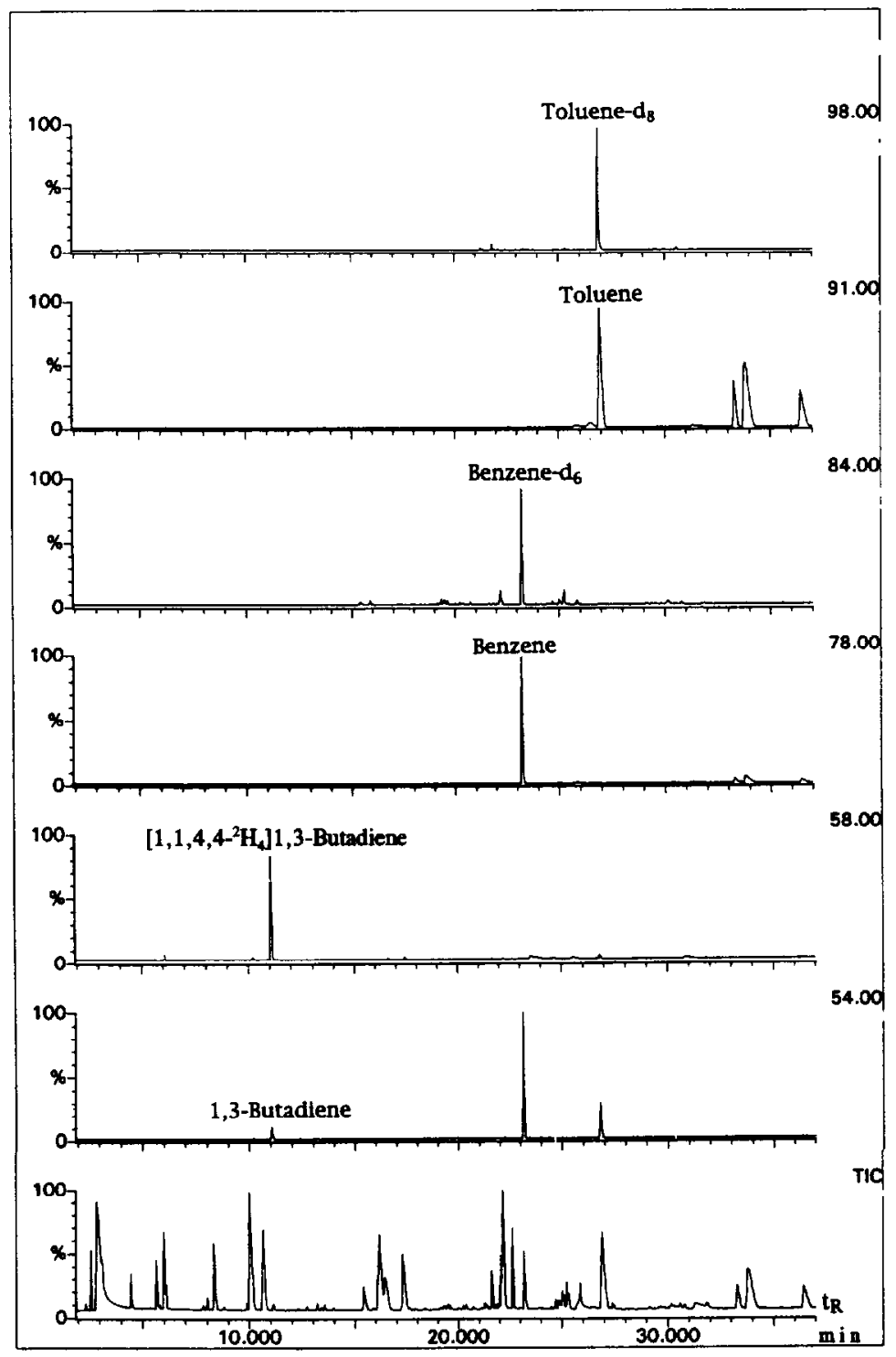

Fig. 4. Mass chromatograms of a tail-pipe exhaust sample.

PLOT column can vary so greatly that methods based on retention times may need to be modified when using columns from different manufacturers [17].

One major reason for the popularity of $\mathrm{GC}$ MS is the introduction of low-cost bench-top GC-MS systems by most MS manufactures. In general, a narrow-bore capillary column is recommended because bench-top GC-MS systems are often equipped with pumps of low pumping speed. It was unfortunate to find, however, that a narrow-bore ( $\leqslant 0.25 \mathrm{~mm}$ I.D.) PLOT column was not commercially available. With the use of a wide-bore column, lower than the optimum flowrate can be an option to meet the pumping speed of bench-top GC-MS. However, with the limitation of the maximum operating temperature $\left(200^{\circ} \mathrm{C}\right)$ of the PLOT column, the use of a low column pressure could result in unreasonably long retention times for large HCs. As an exam- 
Table 1

Concentration and emission rate of toxic hydrocarbons in air and tail-pipe exhaust

\begin{tabular}{|c|c|c|c|c|c|c|}
\hline Sample & \multicolumn{2}{|c|}{ 1,3-Butadiene } & \multicolumn{2}{|l|}{ Benzene } & \multicolumn{2}{|l|}{ Toluene } \\
\hline \multicolumn{7}{|l|}{ Emissions $^{\wedge}$} \\
\hline Motorcycle (ECE) & 8.30 & $(3.6)^{c}$ & 170.95 & $(1.5)^{\mathrm{c}}$ & 541.88 & $(1.6)^{\mathrm{c}}$ \\
\hline \multicolumn{7}{|l|}{ Passenger car (FTP) } \\
\hline Phase 1 & 1.30 & & 152.41 & & 322.83 & \\
\hline Phase 2 & 0.62 & & 30.59 & & 34.15 & \\
\hline Phase 3 & 0.14 & & 54.09 & & 91.70 & \\
\hline Total emission & 0.63 & & 62.30 & & 109.79 & \\
\hline Ambient air $^{\mathrm{b}}$ & 16.18 & $(7.34)^{\mathrm{c}}$ & 151.14 & $(47.47)^{\mathrm{c}}$ & 637.82 & $(169.85)$ \\
\hline
\end{tabular}

ple, with a head pressure of $68.9 \mathrm{kPa}$ and using the temperature program shown in Fig. 3a, the elution times of $o$-xylene and trimethylbenzene were 57 and $80 \mathrm{~min}$, respectively. To reduce the retention times, an open split interface (OSI) [18] consisting of a $1.6 \mathrm{~mm} \mathrm{T-union} \mathrm{and} \mathrm{a} 50$ $\mathrm{cm} \times 100 \mu \mathrm{m}$ I.D. deactivated non-coated fusedsilica column was used for the coupling of GC with MS. The flow into the MS source was limited by the inner diameter and length of the interface column rather than the column head pressure. With this arrangement, while the retention times can be reduced significantly with the use of a higher head pressure, the resolution may not be as good as in low-pressure operation.

To maintain the resolution for $\mathrm{C}_{4} \mathrm{HCs}$ and also reduce the running time, it was found that this goal could be achieved with the use of pressure programming along with an OSI. The flow-rate was kept low at the beginning for the resolution of the $\mathrm{C}_{4} \mathrm{HCs}$ and then raised sharply to reduce the total running time. With a pressure program as shown in Fig. 3b, the elution times of $o$-xylene and trimethylbenzene were reduced to 37 and $47 \mathrm{~min}$, respectively. Another merit of this arrangement is that because of the use of low pressure during the elution of light $\mathrm{HCs}$, the splitting ratio for $\mathrm{C}_{4} \mathrm{HCs}$ is significantly lower than with high-pressure operation. This is especially beneficial for the determination of trace levels of HCs such as 1,3-butadiene.
Because the Fisons GC-MS system used in this study does not have the function of pressure programming, the outlet of a Shimadzu GC-17A gas chromatograph with the capability of pressure-gradient operation was rewired to the thermo desorber. The pressure to the column was controlled by the Shimadzu GC-17A GC instead of the Fisons GC-MS system.

In order to increase the confidence in identification and also in quantification, isotopically labeled internal standards were used for the determination of the major toxic HCs. 1,3Butadiene was determined using $\left[1,1,4,4-{ }^{2} \mathrm{H}_{4}\right]$ 1,3-butadiene, benzene using $\left[{ }^{2} \mathrm{H}_{6}\right]$ benzene, and toluene using $\left[{ }^{2} \mathrm{H}_{8}\right]$ toluene. A typical mass chromatogram of a tail-pipe exhaust sample is shown in Fig. 4. Because isotopic standards have very similar, if not identical, retention times as the analytes, the confidence of identification is higher than with the use of homologs or other compounds as the internal standards. This advantage is more significant considering the relatively poorer reproducibility of retention times with the PLOT column. Moreover, because the analyte and its isotopic analog enter the MS source about the same time, the variation due to the change in instrumental conditions can be eliminated with the use of the relative response factor in quantification.

Deuterium-labeled benzene and toluene were obtained commercially. Deuterium-labeled 1,3- 
butadiene was prepared from solid $[2,2,5,5-$ $\left.{ }^{2} \mathrm{H}_{4}\right]$ butadiene sulfone. By heating the $[2,2,5,5$ ${ }^{2} \mathrm{H}_{4}$ ] butadiene sulfone at $120^{\circ} \mathrm{C}$ for $15 \mathrm{~h}$ in a static dilution bottle, $\left[1,14,4-{ }^{2} \mathrm{H}_{4}\right]$ butadiene could be obtained with an average yield of $95 \%$ (standard deviation $5.34 \%$ ). This approach provides a convenicnt method for preparing $\left[1,1,4,4-{ }^{2} \mathrm{H}_{4}\right]$ butadiene because a solid sample is much easier to handle and can be weighed very accurately. In addition, it is also much cheaper than a gas standard. The deuterium-labeled 1,3-butadiene was determined by GC-FID with pure 1,3butadiene standard. The validity of the quantification of deuterated butadiene with a non-deuterated butadiene standard was checked with benzene- $\left[{ }^{2} \mathrm{H}_{6}\right]$ benzene and toluene- $\left[{ }^{2} \mathrm{H}_{8}\right]$ toluene standards. Known concentrations of deuterated benzene and toluene standards were quantified from the calibration graphs for benzene and toluene, respectively; the results showed that the measured concentrations were within $5 \%$ of the prepared concentrations.

Air collected from roadways and from tailpipe exhausts were analyzed with this approach. Some preliminary results are shown in Table 1. The concentrations of 1,3-butadiene in these samples were much lower than those of benzene and toluene. As expected, the emission rate of phase 1 was higher than those of phase 2 and phase 3 owing to the poorer catalytic efficiency. It is known that temperature greatly affects the efficiency of catalytic converters and the temperature in phase 1 of the driving cycle is not high enough for optimum performance of the converter. Data for a $50 \mathrm{cc}$ two-stroke motorcycle tested with the ECE mode showed that, despite the small engine size, the emission rate of toxic compounds was higher than in passenger car emissions. Different mode of operation, poorer combustion in the engine and the non- catalyst tail-pipe were possible causes of the difference.

\section{References}

[1] E.J. Calabrese and E.M. Kenyon (Editors), Air Toxic and Risk Assessment, Lewis, New York, 1991.

[2] J.M. Peters, F. Lurmann and W. Navidi (Editors), Epidemiologic Investigation to Identify Chronic Health Effects of Ambient Air Pollutants in Southern California, Califorina Air Resources Board Contract A033-186, Phase I Final Report, Part 1, 1992, p. 1.

[3] C.C. Chan, S.H. Lin and G.R. Her, J. Air Waste Manage. Assoc., 43 (1993) 1231.

[4] C.C. Chan, S.H. Lin, C.Y. Tsai and G.R. Her, J. Air Waste Manage. Assoc., 45 (1995) 116.

[5] N. Schmidbauer and M. Oehme, J. High Resolut. Chromatogr. Chromatogr. Commun., 8 (1985) 404.

[6] N. Schmidbauer and M. Oehme, J. High Resolut. Chromatogr. Chromatogr. Commun., 9 (1986) 502.

[7] N. Pelz, N.M. Dempster and P.R. Shore, J. Chromatogr. Sci., $28(1990) 230$.

[8] A. Peters and R. Sacks, J. Chromatogr. Sci., 29 (1991) 403.

[9] J. de Zeeuw, R.C.M. de Nijs and L.T, Henrich, J. Chromatogr. Sci., 25 (1987) 71.

[10] R.A. Lunsford and Y.T. Gagnon, J. High Resolut. Chromatogr. Chromatogr. Commun., 10 (1987) 102.

[11] C.T. Farmer, P.J. Milne, D.D. Riemer and R.G. Zika, Environ. Sci. Technol., 28 (1994) 238.

[12] C.A. Jemma, P.R. Shore, and K.A. Widdicombe, J. Chromatogr. Sci., 33 (1995) 34.

[13] P.G. Simmonds, S. O'Doherty, G. Nickless, G.A. Sturrock, R. Swaby, P. Knight, J. Ricketts, G. Woffendin and R. Smith, Anal. Chem., 67 (1995) 717.

[14] K.L. Olson, R.M. Sinkevitch and T.M. Sloane, J. Chromatogr. Sci., 30 (1992) 500.

[15] R.C.M. de Nijs, J. High Resolut. Chromatogr. Chromatogr. Commun., 4 (1981) 612.

[16] W.L. Mock (Editor), Pericyclic Reactions, Vol. 2, Academic Press, New York, 1977, Ch. 3, p. 92.

[17] H. Heijmans, J. de Zeeuw, J. Buyten, J. Peene and M. Mohnke, Am. Lab., 8 (1994) 28C.

[18] D. Henneberg, U. Henrichs, H. Husmann and G. Schomburg, J. Chromatogr., 167 (1978) 139. 